\title{
Coordination and Partnering Structure are Vital Domains in Collaborative Business-IT Alignment: Elaborating on the ICoNOs MM
}

\author{
Roberto Santana Tapia \\ Department of Computer Science, University of Twente \\ P.O. Box 217, 7500 AE Enschede, The Netherlands \\ r.santanatapia@utwente.nl
}

\begin{abstract}
Current business-IT alignment (B-ITa) maturity models are oriented to single organizations and fail in taking special characteristics of collaborative networked organizations (CNOs) into account, such as the need for considering domains like coordination and partnering structure. In this paper, we elaborate on these two domains which are included in our ITenabled Collaborative Networked Organizations Maturity Model (ICoNOs MM).
\end{abstract}

\section{INTRODUCTION}

In modern organizations, B-ITa is a hard issue that requires continuous attention. There is a considerable literature on measuring and improving B-ITa in single organizations e.g. [1], [2], [3], but the problem of B-ITa in CNOs has hardly been studied.

In this paper, we introduce the coordination and partnering structure domains included in our ICoNOs MM. The ICoNOs MM is a MM to assess B-ITa in CNO settings. It helps to identify points of improvement, and to plan steps to take toward better alignment. From our research we have strong indications that, even if the architectures of information systems (ISs) and processes are properly taken into account in collaborative BITa projects, coordination and partnering structure must also be considered by CNOs assuring more positive results in such projects.

\section{Assessing Collaborative B-ITA}

Assessing B-ITa involves looking in different B-ITa domains in order to identify opportunities of improvement in organizations on some particular areas. As no current B-ITa MM addresses alignment in CNOs and no other MM addresses more than a single aspect of B-ITa - see [4], we are filling this gap by developing the ICoNOs MM to assess B-ITa in CNO settings, i.e., to assess collaborative B-ITa.

Talking about B-ITa commonly leads one to think in aspects related to technology, processes, and/or (strategic) goals. However, in collaborative B-ITa projects, beside these aspects, coordination and partnering structure are vital for assuring the success of the projects. Evidence from case studies - see [5], conducted to design the ICoNOs MM supports such a claim.

The author is supported by the Netherlands Organization for Scientific Research under contract no. 638.003.407 (Value-Based Business-IT Alignment).
We define coordination as the mechanisms to manage the interaction and work among the participating organizations taking into account the dependencies and the shared resources among the processes. Beside coordination, partnering structure must also be considered when striving for collaborative B-ITa. Our case studies have revealed that the partnering structure domain always must be attended to when improving B-ITa because it can contain critical obstacles towards such an improvement. By partnering structure we mean the cross-organizational work division, organizational structure, and roles and responsibilities definition that indicate where and how the work gets done and who is involved.

\section{THE ICONOS MM}

The ICoNOs MM can be seen as a two dimensional framework (see Fig. 1). These dimensions represent the maturity levels and the domains to which these levels apply. The ICoNOs MM has five levels of maturity and includes four domains: partnering structure, IS architecture, process architecture and coordination.

The cells of the ICoNOs MM contain B-ITa process areas. For a detailed definition of these process areas, please refer to our previous work [4]. We make an explicit note that, when finalizing the development of the ICoNOs MM, we have changed the position of some of the process areas presented in the previous version of the MM [4]. We found that some of the process areas are strongly related to each other. We then decided to re-arrange de position of them, so that some of the original process areas are now goals of, or practices in, another process area. For example, the "inter-organizational policies definition" and the "roles and responsibilities specification" process areas in level three of the partnering structure domain [4] are now included in the "governance structure and compliance" - GSC - process area.

In the remainder of this section we elaborate on the coordination and partnering structure domains presenting the specific goals (SGs) and the specific practices (SPs) involved in each process area. We only introduce the SGs and SPs included in the levels two and three in these domains because in these two levels is where CNOs can make the most significant improvements. We list the process areas in alphabetical order. 


\begin{tabular}{|c|c|c|c|c|c|c|c|c|}
\hline & \multicolumn{2}{|c|}{ PARTNERING STRUCTURE } & \multicolumn{2}{|l|}{ IS ARCHITECTURE } & \multicolumn{2}{|l|}{ PROCESS ARCHITECTURE } & \multicolumn{2}{|l|}{ COORDINATION } \\
\hline 5 & & & $\begin{array}{l}\text { Inter-organizational IS arch. optimization } \\
\text { Risk analysis and mitigation }\end{array}$ & $\begin{array}{l}\text { IOAO } \\
\text { RAM }\end{array}$ & $\begin{array}{l}\text { Inter-organizational process optimization } \\
\text { Causal analysis and resolution }\end{array}$ & $\begin{array}{l}\text { IOPO } \\
\text { CAR }\end{array}$ & & \\
\hline 4 & Metric-based roles exploration & MRE & Quantitative IS portfolio management & QPM & $\begin{array}{l}\text { Organizational process performance } \\
\text { Event logs formal consistency }\end{array}$ & $\begin{array}{l}\text { OPP } \\
\text { EFC }\end{array}$ & $\begin{array}{l}\text { Quantitative coordination relation } \\
\text { analysis }\end{array}$ & QRA \\
\hline 3 & $\begin{array}{l}\text { Governance structure and } \\
\text { compliance }\end{array}$ & GSC & $\begin{array}{l}\text { IS requirements management } \\
\text { IS capabilities definition } \\
\text { IS portfolio management }\end{array}$ & $\begin{array}{l}\text { ISRM } \\
\text { ISCD } \\
\text { ISPM }\end{array}$ & $\begin{array}{l}\text { Organizational process focus planning } \\
\text { Target process architecture formulation }\end{array}$ & $\begin{array}{l}\text { PFP } \\
\text { TPA }\end{array}$ & $\begin{array}{l}\text { Standardization } \\
\text { Communication-oriented coordination }\end{array}$ & $\begin{array}{l}\text { STD } \\
\text { COC }\end{array}$ \\
\hline 2 & $\begin{array}{l}\text { Business model definition } \\
\text { Service level agreements definition }\end{array}$ & $\begin{array}{l}\text { BMD } \\
\text { SLA }\end{array}$ & Current IS architecture description & CSA & $\begin{array}{l}\text { Current process architecture } \\
\text { description }\end{array}$ & CPD & $\begin{array}{l}\text { Informal communication adjustment } \\
\text { Direct supervision }\end{array}$ & $\begin{array}{l}\text { InCA } \\
\text { DTS }\end{array}$ \\
\hline 1 & & & & & & & & \\
\hline
\end{tabular}

Fig. 1. The ICoNOs MM.

\section{A. Coordination}

Communication-oriented coordination [COC]

A process area at maturity level 3 .

\section{Specific goals and practices}

SG1 Agree about communication channels and a common language.

SG2 Create a sharing knowledge considering inside/outside information.

SG3 Bring participants to a required level of understanding for work

SG4 Use IT to enable the communication between the participants.

SG5 Ensure that participants use continuous learning to respond to immediate needs.

Direct supervision [DTS]

A process area at maturity level 2 .

Specific goals and practices

SG1 Plan the supervision.

SP1.1 Define the strategy.

SP1.2 Choose the supervisory model.

SP1.3 Examine the plan.

SG2 Establish a safe and trust relation with the supervisees.

SP2.1 Meet the supervisees.

SP2.2 Present the supervisory plan.

SG3 Monitor the ongoing activities.

SG4 Provide instructions to adjust problems.

SG5 Build a learning agenda.

Informal communication adjustment [InCA]

A process area at maturity level 2 .

Specific goals and practices

SG1 Identify the social composition of the CNO.

SP1.1 Identify the relationship-based structures.

SP1.2 Establish the communities of practice.

SP1.3 Identify the unofficial agreed-on processes.

SG2 Define and shape productive informal communication.

SG3 Promote extracurricular activities.

SP3.1 Plan the extracurricular activities.

SP3.2 Encourage the attendance of the participants.

SG4 Influence the development of the informal structure.

SG5 Acknowledge contribution to improvement of informal communication.

Standardization [STD]

A process area at maturity level 3 .

Specific goals and practices

SG1 Standardize processes.

SP1.1 Identify processes that are candidates for standardization.

SP1.2 Design the general work processes ensuring coordination.

SP1.3 Diffuse the standardized processes between participants.

SG2 Standardize skills.

SP2.1 Define norms for work skills and required skills.

SP2.2 Make an inventory of the participants' skills.

SP2.3 Educate and train participants in the same skills.

SP2.4 Share values and ethical standards.

SP2.5 Evaluate the skills.

SG3 Standardize outputs.

\section{B. Partnering Structure}

Business model definition [BMD]

A process area at maturity level 2 .

Specific goals and practices

SG1 Define the CNO overall identity.

SP1.1 Identify the mission and vision of the CNO.

SP1.2 Identify useful internal assets

SP1.3 Describe the product or service provided.
SP1.4 Identify the competitive advantage of the CNO

SG2 Identify the external environment

SP2.1 Describe the target market (group of customers) of the CNO.

SP2.2 Define the supporting institutions (e.g. suppliers, technological partners, chamber of commerce, government entities, financial institutions, etc.).

SP2.3 Identify the competitors.

SG3 Describe a multi-value configuration.

SP3.1 Define the cost structure.

SP3.2 Construct a value model.

SP3.3 Describe the revenue model.

SG4 Formulate an overall CNO plan.

SP4.1 Describe the specific goals to achieve.

SP4.2 Set a timeframe for achieving the goals.

SP4.3 Define performance indicators.

Governance structure and compliance [GSC]

A process area at maturity level 3 .

Specific goals and practices

SG1 Describe the overall organizational structure.

SP1.1 Depict the CNO chart.

SP1.2 Specify the roles and responsibilities.

SP1.3 Define the distribution of property rights.

SG2 Define the inter-organizational policies.

SP2.1 Formulate the business rules.

SP2.2 Define share risks and reward policies.

SP2.3 Specify decision-making procedures.

SG3 Define the CNO directions.

SP3.1 Build a program activity architecture.

SP3.2 Set priorities and plans

SP3.3 Develop a performance measurement framework

SG4 Ensure activities compliance.

SP4.1 Identify processes and control objectives.

SP4.2 Conduct a risk assessment

SP4.3 Confirm adequacy and solve discrepancies.

Service level agreements definition [SLA]

A process area at maturity level 2 .

Specific goals and practices

SG1 Negotiate the agreements.

SP1.1 Determine performance thresholds.

SP1.2 Define measurable commitments,

SP1.3 Document the agreements.

SG2 Describe SLA control issues.

SP2.1 Agree on escalation procedures.

SP2.2 Establish penalties and incentives.

\section{REFERENCES}

[1] D. de Koning and P. van der Marck, IT Zonder Hoofdpijn: Een Leidraad voor het Verbeteren van de Bedrijfsprestaties. Prentice Hall, 2002,(Dutch).

[2] J. Duffy, "Maturity models: Blueprints for e-volution," Strategic and Leadership, vol. 29, no. 6, pp. 19-26, 2001.

[3] J. N. Luftman, "Assessing IT-business alignment," Information Systems Management, vol. 20, no. 4, pp. 9-15, 2003.

[4] R. Santana Tapia, M. Daneva, P. van Eck, and R. Wieringa, "Towards a business-IT alignment maturity model for collaborative networked organizations," in Proceedings of the International Workshop on Enterprise Interoperability (IWEI 2008), Munich, Germany, ser. CTIT Workshop Proceedings WP08-05. CTIT, 2008, pp. 70-81.

[5] R. Santana Tapia, M. Daneva, P. van Eck, N. Castro Cárdenas, and L. van Oene, "Business-IT alignment domains and principles for networked organizations: A qualitative multiple case study," in On the Move to Meaningful Internet Services: OTM 2008 Workshops Proceedings, Monterrey, Mexico, ser. LNCS. Springer Verlag, 2008, pp. 241-252. 